\title{
Fundamental Drop Dynamics and Mass Transfer Experiments to Support Solvent Extraction Modeling Efforts
}

Kristi Christensen

Veronica Rutledge

Troy Garn

Jack Law

September 2011

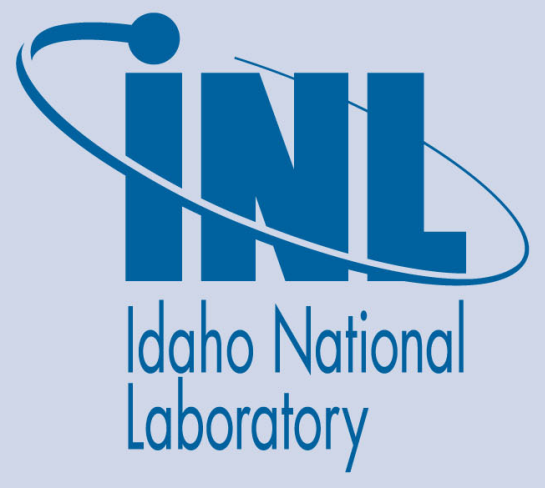

The INL is a U.S. Department of Energy National Laboratory operated by Battelle Energy Alliance 
INL/EXT-11-23426

FCRD-SWF-2011-000363

\title{
Fundamental Drop Dynamics and Mass Transfer Experiments to Support Solvent Extraction Modeling Efforts
}

\author{
Kristi Christensen \\ Veronica Rutledge \\ Troy Garn \\ Jack Law
}

September 2011

\author{
Idaho National Laboratory \\ Fuel Cycle Research \& Development \\ Idaho Falls, Idaho 83415
}

http://www.inl.gov

Prepared for the

U.S. Department of Energy

Office of Nuclear Energy

Under DOE Idaho Operations Office

Contract DE-AC07-05ID14517 


\section{DISCLAIMER}

This information was prepared as an account of work sponsored by an agency of the U.S. Government. Neither the U.S. Government nor any agency thereof, nor any of their employees, makes any warranty, expressed or implied, or assumes any legal liability or responsibility for the accuracy, completeness, or usefulness, of any information, apparatus, product, or process disclosed, or represents that its use would not infringe privately owned rights. References herein to any specific commercial product, process, or service by trade name, trade mark, manufacturer, or otherwise, does not necessarily constitute or imply its endorsement, recommendation, or favoring by the U.S. Government or any agency thereof. The views and opinions of authors expressed herein do not necessarily state or reflect those of the U.S. Government or any agency thereof. 


\section{SUMMARY}

In support of the Nuclear Energy Advanced Modeling Simulation Safeguards and Separations (NEAMS SafeSep) program, the Idaho National Laboratory (INL) worked in collaboration with Los Alamos National Laboratory (LANL) to further a modeling effort designed to predict mass transfer behavior for selected metal species between individual dispersed drops and a continuous phase in a two phase liquidliquid extraction (LLE) system. The purpose of the model is to understand the fundamental processes of mass transfer that occur at the drop interface. This fundamental understanding can be extended to support modeling of larger LLE equipment such as mixer settlers, pulse columns, and centrifugal contactors.

The work performed at the INL involved gathering the necessary experimental data to support the modeling effort. A custom experimental apparatus was designed and built for performing drop contact experiments to measure mass transfer coefficients as a function of contact time. A high speed digital camera was used in conjunction with the apparatus to measure size, shape, and velocity of the drops. In addition to drop data, the physical properties of the experimental fluids were measured to be used as input data for the model. Physical properties measurements included density, viscosity, surface tension and interfacial tension. Additionally, self diffusion coefficients for the selected metal species in each experimental solution were measured, and the distribution coefficient for the metal partitioning between phases was determined.

At the completion of this work, the INL has determined the mass transfer coefficient and a velocity profile for drops rising by buoyancy through a continuous medium under a specific set of experimental conditions. Additionally, a complete set of experimentally determined fluid properties has been obtained. All data will be provided to LANL to support the modeling effort. 


\section{CONTENTS}

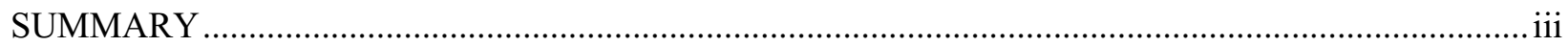

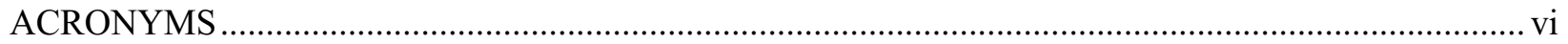

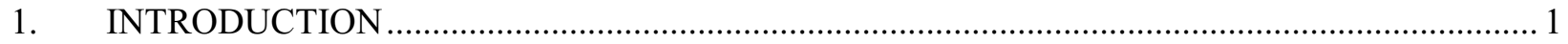

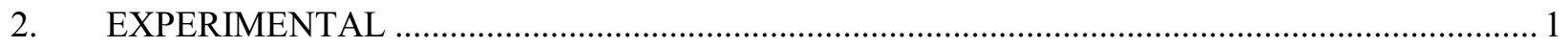

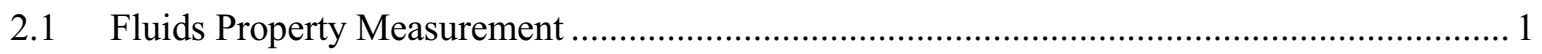

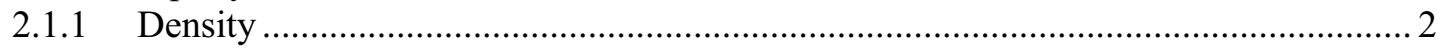

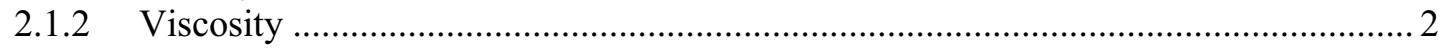

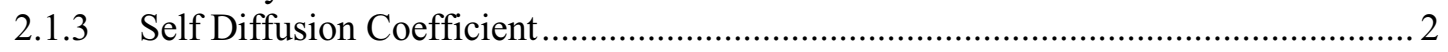

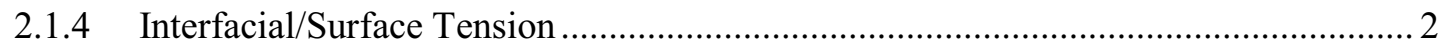

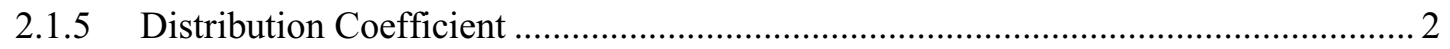

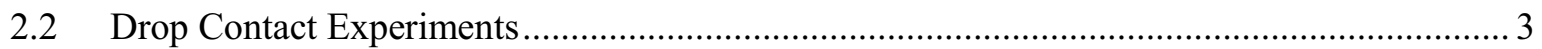

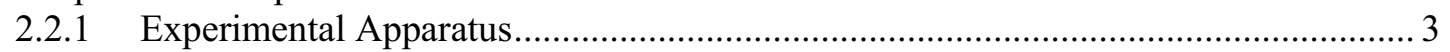

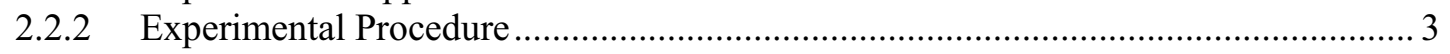

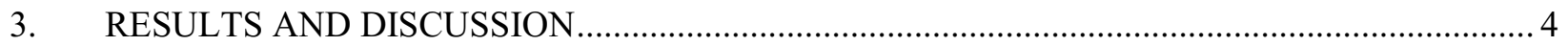

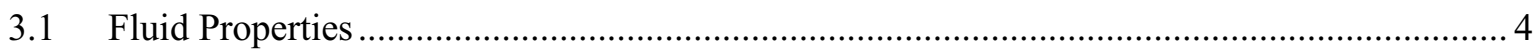

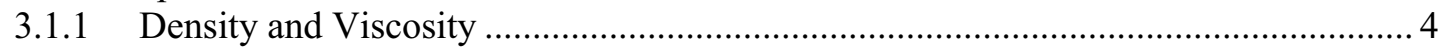

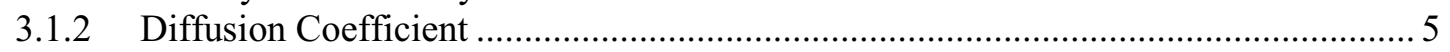

3.1.3 Interfacial/Surface Tension ................................................................... 5

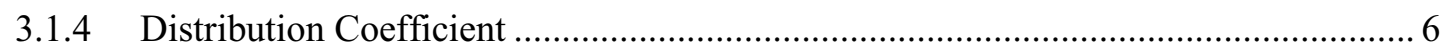

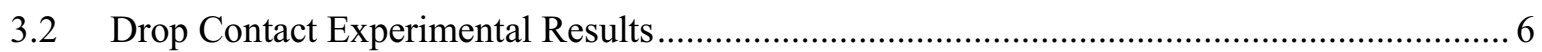

3.2.1 Drop Size and Deformation ............................................................. 7

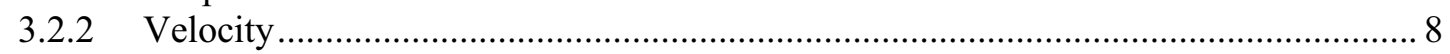

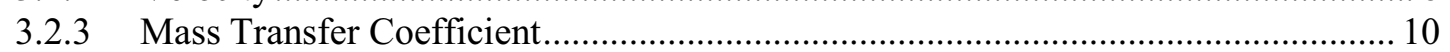

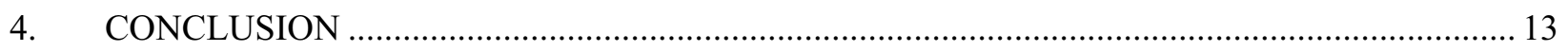

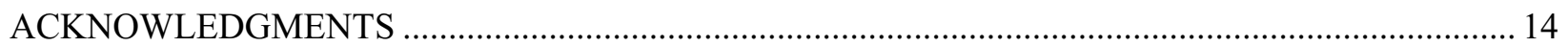

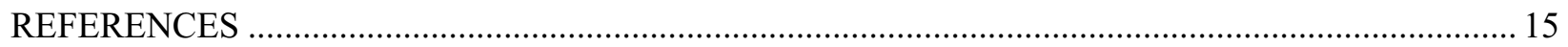




\section{FIGURES}

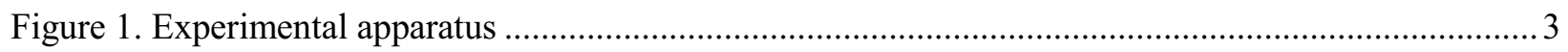

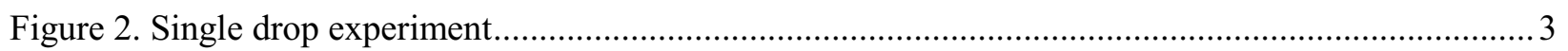

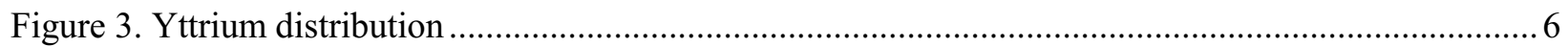

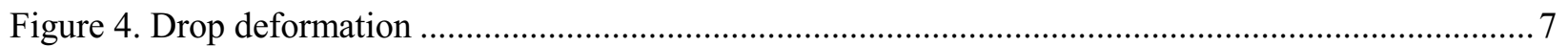

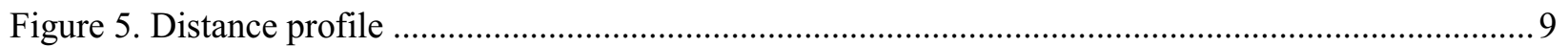

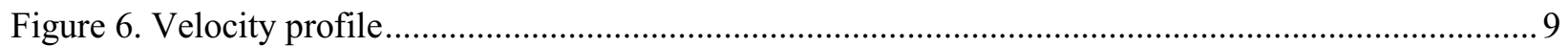

Figure 7. Concentration in the organic drop as a function of time …..................................................... 11

Figure 8. Mass transfer coefficient as a function of time......................................................................... 12

\section{TABLES}

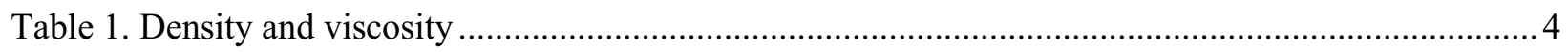

Table 2. Diffusion coefficients for yttrium in extraction solutions.............................................................5

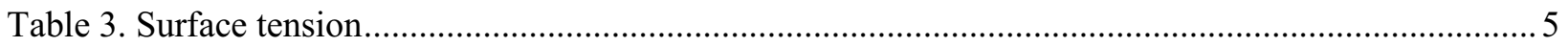

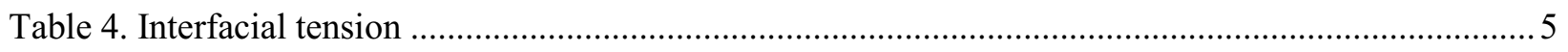

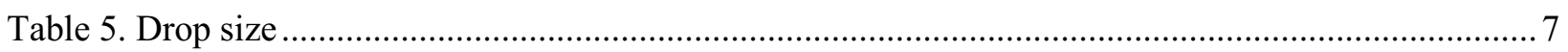

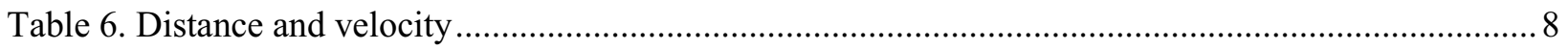

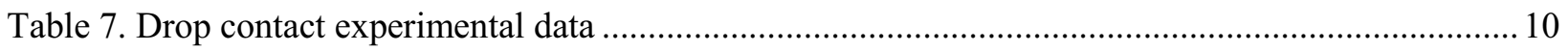

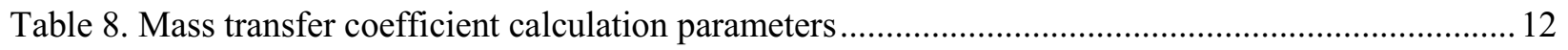




\section{ACRONYMS}

AMUSE Argonne Model for Universal Solvent Extraction

CMPO octyl(phenyl)-N, N-dibutyl carbamoylmethyl phosphine oxide

HEDPA 1-hydroxyethane-1, 1-diphosphonic acid

ICP-MS Inductive Coupling Plasma-Mass Spectroscopy

INL Idaho National Laboratory

LANL Los Alamos National Laboratory

LLE Liquid-Liquid Extraction

OECM Open End Capillary Method

NEAMS Nuclear Energy Advanced Modeling and Simulation

SafeSep Safeguards and Separations

TBP Tributylphosphate

TRUEX TRansUranic EXtraction 


\section{FUEL CYCLE RESEARCH AND DEVELOPMENT/SEPARATIONS AND WASTE FORMS FUNDAMENTAL DROP DYNAMICS AND MASS TRANSFER EXPERIMENTS TO SUPPORT SOLVENT EXTRACTION MODELING EFFORTS}

\section{INTRODUCTION}

In support of the NEAMS SafeSep modeling effort, the INL worked in collaboration with LANL to further develop accurate simulations of the effects of drop dynamics on mass transfer in two phase LLE systems. Understanding the association of drop dynamics to mass transfer is of great importance in LLE processes. Drop scale experiments and simulations improve understanding of mass transfer at the drop interface. This understanding can be extended to support modeling of larger LLE equipment such as mixer settlers, pulse columns, and centrifugal contactors.

The work performed at the INL involved gathering necessary experimental data to support the modeling effort. A custom experimental apparatus was designed and built for performing drop contact experiments to measure mass transfer rates. Experiments were performed using solutions common to the TRans Uranic EXtraction (TRUEX) process. The TRUEX process was selected because it is one of the solvent extraction systems currently proposed for the separation of actinides and lanthanides from used nuclear fuel, it is a diffusion limited process, and testing could be performed using non-radioactive surrogate metal species. In addition to mass transfer rates, the physical properties of each fluid were measured for use as input data for the model.

\section{EXPERIMENTAL}

\subsection{Fluids Property Measurement}

The drop contact experiment was conducted with solutions used in the extraction section of the TRUEX process. The extraction section of the TRUEX process involves transfer of one or more metal species from an acidic aqueous solution into an organic solvent. The TRUEX solvent is comprised of $0.2 \underline{\mathrm{M}}$ octyl(phenyl)-N, N-dibutyl carbamoylmethyl phosphine oxide (CMPO) and $1.4 \underline{\mathrm{M}}$ tributylphosphate (TBP) in an Isopar-L diluent. The aqueous solution is $3 \underline{M}$ nitric acid loaded with an extractable metal species. Prior to performing the drop contact experiment, the organic solution was pre-equilibrated with 3 $\underline{\mathrm{M}}$ nitric acid to ensure the $\mathrm{H}^{+}$concentration in the organic solvent was in equilibrium with the aqueous solution so only metal species mass transfer occurred during experimentation.

In addition to measuring the fluid properties of the extraction fluids described above, the fluid properties of solutions used in the strip section of the TRUEX process were also measured. While the drop contact experiment discussed in this report used the TRUEX extraction fluids, the strip solution properties were measured to support potential future work. The TRUEX strip section involves transfer of metals from the organic solvent to an aqueous strip solution. The aqueous strip solution evaluated is $0.005 \mathrm{M} 1$ hydroxyethane-1, 1-diphosphonic acid (HEDPA) in $0.1 \underline{\mathrm{M}}$ nitric acid. The organic solvent is the same as described above, except that it is pre-equilibrated with $0.1 \underline{\mathrm{M}}$ nitric acid, rather than $3 \underline{\mathrm{M}}$ nitric acid, and loaded with the extractable metal species. 
Cerium and yttrium were chosen as the extractable metal species. Cerium was chosen as the lanthanide representative for metals present in the actual TRUEX process. Yttrium, also an element present in used nuclear fuel, was chosen because it was predicted to have a lower distribution coefficient between the two extraction solutions and could be used to compare the effects of distribution coefficient on mass transfer rates for modeling purposes.

\subsubsection{Density}

Densities were measured using a Mettler Toledo analytical balance. To provide statistical data, a minimum of three measurements were taken for each fluid.

\subsubsection{Viscosity}

Viscosity was measured using a Cambridge Applied Systems Viscometer.

\subsubsection{Self Diffusion Coefficient}

Self diffusion coefficients were measured using the open end capillary method (OECM) ${ }^{1-2}$ This method involves filling volume calibrated capillaries of length $L$ with a solution containing a known concentration of metal spiked with a radiotracer isotope of the same metal. The filled capillary is contacted with a solution of the same composition excluding the radioisotope. The amount of radioactivity diffused from the capillary to the non-radioactive solution is measured as a function of time. By solving Fick's equation, the diffusion coefficient (D) can be related to amount of activity transferred out of the capillary as follows:

$$
\frac{C(x, t)}{C_{0}(x, 0)}=\sum_{n=0}^{\infty} \frac{8}{\pi^{2}(2 n+1)} \exp \left[-\pi^{2}(2 n+1)^{2} \frac{D t}{4 L^{2}}\right]
$$

Equation 1

where $t$ is time, $C(x, t)$ is the concentration of radioisotope in the capillary at time $\mathrm{t}$, and $C_{0}(x, 0)$ is the initial concentration of radioisotope in the capillary at time 0 .

\subsubsection{Interfacial/Surface Tension}

Interfacial and surface tension measurements were performed through a subcontract with University of Idaho. Surface tension was measured by both the Wilhelmy Plate method and the drop-weight method, while interfacial tension measurements were performed by the drop-weight method only.

\subsubsection{Distribution Coefficient}

The distribution coefficient was obtained by performing a series of batch contacts with varying initial concentrations of metal in the aqueous phase. Equal volumes of aqueous and organic solutions were mixed at ambient temperature for a period of time sufficient to achieve equilibrium. The mixture was then centrifuged to ensure complete phase disengagement. Samples of each phase were taken, and the resulting concentrations were determined by inductive coupling plasma-mass spectroscopy (ICP-MS). The data was plotted and fit by linear regression to obtain a value for the distribution coefficient $(\mathrm{m})$, defined as:

$$
m=\frac{c_{0, e q}}{C_{A q, e q}}
$$

Equation 2

where $C_{O, \theta q}$ is the organic phase metal concentration at equilibrium, and $C_{A q, \theta q}$ is the aqueous phase metal concentration at equilibrium. 


\subsection{Drop Contact Experiments}

\subsubsection{Experimental Apparatus}

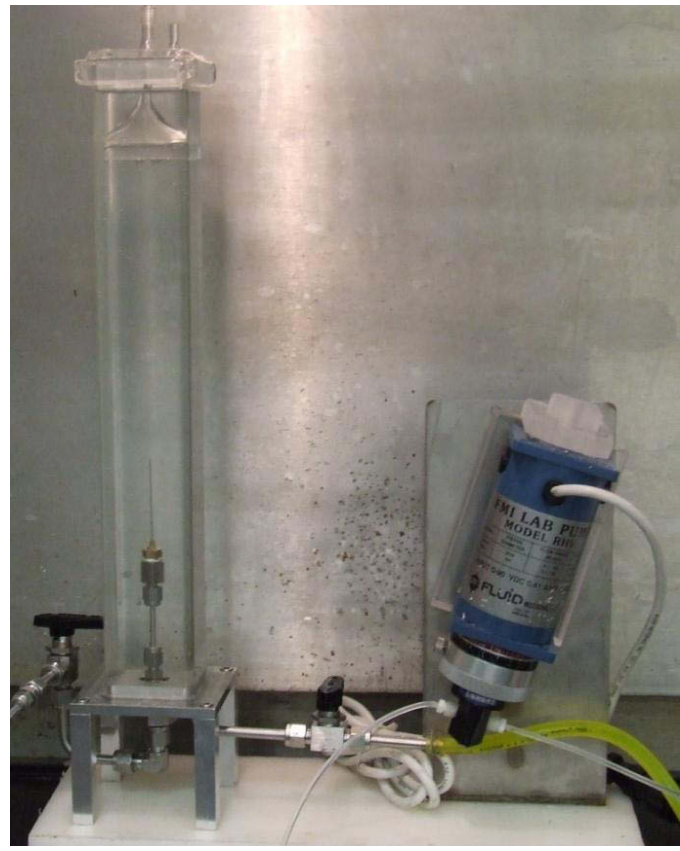

Figure 1. Experimental apparatus
Figure 1 shows the custom apparatus that was designed and built for drop contact experiments. The apparatus is similar in design to vessels used for drop contact experiments found in literature..$^{3-6}$ The vessel was constructed from quartz glass to eliminate distortions while imaging rising drops with a high speed digital camera. The glass portion of the vessel is rectangular with dimensions of $51 \mathrm{~mm} \times 51 \mathrm{~mm} \times 380 \mathrm{~mm}$, and holds approximately 1 liter of solution. The glass is attached to a machined stainless steel base plate that allows for ease of needle change out. During experimentation, organic drops were introduced into aqueous media via the needle assembly. Needle orifice size can be varied to achieve multiple drop diameters. The needle height is adjustable to control drop rise time. The tapered organic collection chamber was designed to minimize the contact time between the two phases during drop coalescence and to enable ease of sampling. A metering pump (FMI Metering Inc., Model: RHV-1) and controller (FMI Metering Inc., Model V200) were used to regulate organic flow rate to provide consistency in drop size.

\subsubsection{Experimental Procedure}

Drop contact experiments were performed by filling the apparatus with aqueous solution and pumping organic solution through the needle assembly. Drops formed at the needle orifice, and then buoyancy forces caused the drops to rise to the top of the vessel where they coalesced in the organic collection chamber. To determine the mass transfer coefficient as a function of rise time, an experiment consisted of six runs with six different needle heights. At the end of each run, organic and aqueous samples were collected and analyzed by ICP-MS. Drop size, contact time, and drop velocity were evaluated using a high speed digital camera (Phantom, V7.3, Model: VRI-V7.1-4096MC). The experiment was performed as a "single drop" experiment, meaning that the organic flow rate was set such that each drop was introduced into the aqueous phase with sufficient spacing to avoid drop interaction. Figure 2 shows a visual representation of a single drop experiment. In order to have sufficient organic volume for analysis, multiple drops coalesced in the organic collection chamber. Organic sample was collected from the chamber using a syringe and needle. The interface height was kept constant by withdrawing the organic sample as the experiment progressed. A constant interface height maintained a constant drop rise distance, thereby maintaining a constant rise time for each needle height.

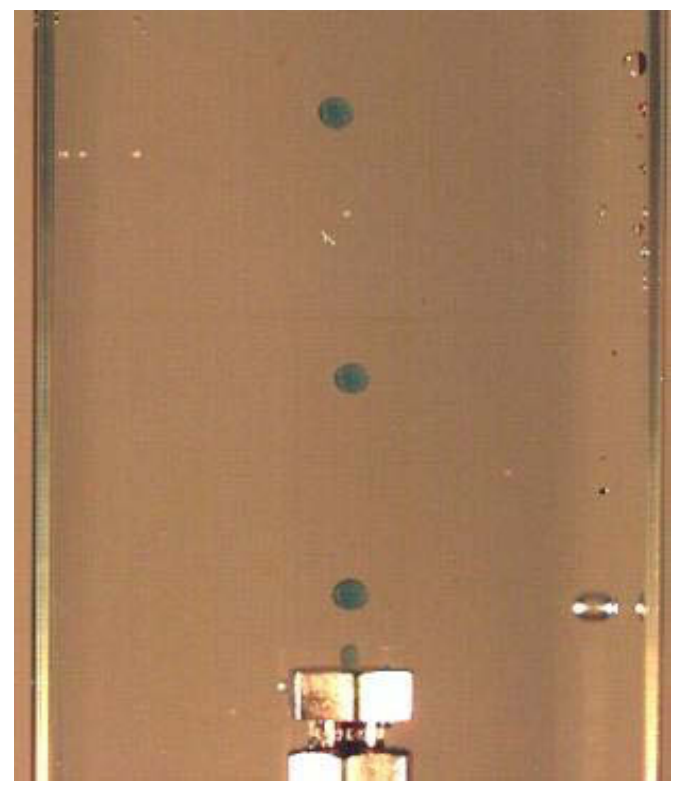

Figure 2. Single drop experiment 


\section{RESULTS AND DISCUSSION}

\subsection{Fluid Properties}

\subsubsection{Density and Viscosity}

The measured densities and viscosities of the various fluids are summarized in Table 1. The first four entries in the table are measurements of the TRUEX extraction and strip section solutions with no metals present. Additionally, measurements were performed on $3 \underline{\mathrm{M}}$ nitric acid containing $\mathrm{Y}, 3 \underline{\mathrm{M}}$ nitric acid containing Ce, and TRUEX pre-equilibrated with $0.1 \underline{\mathrm{M}}$ nitric acid containing Ce. These solutions were selected for measurement because they are the proposed metal containing starting solutions for $\mathrm{Y}$ extraction, Ce extraction, and Ce strip drop contact experiments, respectively.

Table 1. Density and viscosity

\begin{tabular}{lcc}
\hline Solution & Density $(\mathrm{g} / \mathrm{mL})$ & Viscosity (cP) \\
\hline \hline $\begin{array}{l}\text { TRUEX Pre-equilibrated } \\
\text { with } 0.1 \underline{\mathrm{M}} \mathrm{HNO}_{3}\end{array}$ & $0.874 \pm 0.008$ & $3.235 \pm 0.294$ \\
$\begin{array}{l}\text { TRUEX Pre-equilibrated } \\
\text { with } 3 \underline{\mathrm{M}} \mathrm{HNO}_{3}\end{array}$ & $0.894 \pm 0.008$ & $3.817 \pm 0.172$ \\
$3 \underline{\mathrm{M}} \mathrm{HNO}_{3}$ & $1.116 \pm 0.002$ & $1.220 \pm 0.012$ \\
$0.005 \underline{\mathrm{M}} \mathrm{HEDPA}$ & & \\
in $0.1 \underline{\mathrm{M}} \mathrm{HNO}_{3}$ & $1.010 \pm 0.004$ & $0.986 \pm 0.003$ \\
$3 \underline{\mathrm{M}} \mathrm{HNO}_{3}$ & $1.114 \pm 0.006$ & $1.101 \pm 0.007$ \\
with $0.1 \mathrm{~g} / \mathrm{L} \mathrm{Ce}$ & $1.105 \pm 0.003$ & $1.110 \pm 0.006$ \\
$3 \underline{\mathrm{M}} \mathrm{HNO}_{3}$ & & \\
with 0.064 g/L Y & $0.878 \pm 0.001$ & $2.917 \pm 0.024$ \\
$*$ Pre-equilibrated TRUEX with & & \\
$0.70 \mathrm{~g} / \mathrm{L} \mathrm{Ce}$ & &
\end{tabular}

*TRUEX was pre-equilibrated with $0.1 \underline{\mathrm{M}}$ nitric acid, and then was contacted with an equal volume of 0.1 $\underline{\mathrm{M}}$ nitric acid containing $1.5 \mathrm{~g} / \mathrm{L}$ cerium. The resulting concentration in the TRUEX was $0.70 \mathrm{~g} / \mathrm{L} \mathrm{Ce}$.

The measured density and viscosity values are consistent with expected results. The viscosities of the 3 $\underline{\mathrm{M}}$ nitric acid solutions are slightly higher than the viscosity of pure water $\left(1.002 \mathrm{cP} \text { at } 20^{\circ} \mathrm{C}\right)^{7}$, while the viscosity of the strip solution is slightly less. As expected, the densities of all aqueous solutions are slightly greater than the density of pure water $\left(0.99821 \mathrm{~g} / \mathrm{mL} \text { at } 20^{\circ} \mathrm{C}\right)^{7}$. The densities of the TRUEX solutions are slightly higher than the densities of both Isopar-L $\left(0.77 \mathrm{~g} / \mathrm{mL} \text { at } 20^{\circ} \mathrm{C}\right)^{8}$ and TBP $(0.812$ $\mathrm{g} / \mathrm{mL}$ at $\left.20^{\circ} \mathrm{C}\right)^{7}$, but this is expected due to the addition of CMPO and the nitric acid used for preequilibration. Comparing the results for the three TRUEX solutions, it appears that the acid concentration used for pre-equilibration has a significant impact on density, with higher acid concentration equating to a higher density; meanwhile the addition of metal had little effect. The measured viscosities for the organic solutions are higher than the value of $1.6 \mathrm{cP}^{8}$ reported for Isopar-L, but again this is likely due to the presence of TBP, CMPO, and nitric acid in the solution. In addition to a higher density, an increase in acid concentration also resulted in a higher viscosity. However, unlike density results, the presence of metal appears to have a significant impact on viscosity, resulting in a considerably lower viscosity value. 


\subsubsection{Diffusion Coefficient}

Diffusion coefficient results are shown in Table 2. The work completed in FY-11 only included diffusion coefficients for $Y$ diffusion in the extraction solutions (3 $\underline{M}$ nitric acid and TRUEX pre-equilibrated with $3 \underline{\mathrm{M}}$ nitric acid). $\mathrm{Y}^{88}$ was used as the radioisotope for this work.

Table 2. Diffusion coefficients for yttrium in extraction solutions

\begin{tabular}{cc}
\hline Solution & $\begin{array}{c}\text { Diffusion Coefficient } \\
\left(10^{-5} \mathrm{~cm}^{2} / \mathrm{s}\right)\end{array}$ \\
\hline \hline $\begin{array}{c}\text { TRUEX Pre-equilibrated } \\
\text { with } 3 \underline{\mathrm{M}} \mathrm{HNO}_{3}\end{array}$ & $4.0 \pm 0.6$ \\
$3 \underline{\mathrm{M} \mathrm{HNO}_{3}}$ & $2.8 \pm 0.3$ \\
\hline
\end{tabular}

The aqueous diffusion coefficient compares well to reported data. Latrous and Oliver found self diffusion coefficients of approximately $6.0 \times 10^{-6} \mathrm{~cm}^{2} / \mathrm{s}$ in a study of self diffusion coefficients for actinide metals in acidic aqueous solutions. ${ }^{1}$ The yttrium diffusion coefficient in $3 \underline{\mathrm{M}}$ nitric acid is slightly higher than their reported results; however, this is expected due to the smaller molecular size of yttrium relative to the actinides. No information was found for comparison to the diffusion coefficient for yttrium in the organic solution.

\subsubsection{Interfacial/Surface Tension}

Results for surface tension are reported in Table 3, and results for interfacial tension are reported in Table 4. Surface tension measurements were performed on extraction and strip section solutions, and interfacial tensions were performed on the extraction and strip section solvent pairs. It was predicted that the presence of metals, in the concentrations used for drop contact experiments, would not have a significant impact on surface tension and interfacial tension values; therefore, measurements were not performed on solutions with metal.

Table 3. Surface tension

\begin{tabular}{ccc}
\hline Solution & $\begin{array}{c}\text { Wilhelmy Plate } \\
(\mathrm{mN} / \mathrm{m})\end{array}$ & Drop-Weight $(\mathrm{mN} / \mathrm{m})$ \\
\hline TRUEX pre-equilibrated with $3 \underline{\mathrm{M}} \mathrm{HNO}_{3}$ & $25.9 \pm 0.1$ & $33.4 \pm 0.9$ \\
TRUEX pre-equilibrated with $0.1 \underline{\mathrm{M}} \mathrm{HNO}_{3}$ & $25.2 \pm 1.0$ & $35.0 \pm 0.8$ \\
$0.005 \underline{\mathrm{M}} \mathrm{HEDPA}$ in 0.1 $\underline{\mathrm{M}} \mathrm{HNO}_{3}$ & $71.0 \pm 0.4$ & $72.7 \pm 4.0$ \\
$3 \underline{\mathrm{M}} \mathrm{HNO}_{3}$ & $62.3 \pm 3.2$ & $72.2 \pm 0.7$ \\
\hline
\end{tabular}

Table 4. Interfacial tension

Aqueous Solvent $\quad$ Organic Solvent Interfacial Tension $(\mathrm{mN} / \mathrm{m})$

\begin{tabular}{ccc}
\hline \hline$\underline{\mathrm{M} \mathrm{HNO}_{3}}$ & $\begin{array}{c}\text { TRUEX pre-equilibrated } \\
\text { with } 3 \underline{\mathrm{M}} \mathrm{HNO}_{3}\end{array}$ & $13.2 \pm 0.6$ \\
$0.005 \underline{\mathrm{M}} \mathrm{HEDPA}$ & $\begin{array}{c}\text { TRUEX pre-equilibrated } \\
\text { with } 0.1 \underline{\mathrm{M}} \mathrm{HNO}_{3}\end{array}$ & $10.2 \pm 0.2$ \\
\hline in $0.1 \underline{\mathrm{M}} \mathrm{HNO}_{3}$ & w & \\
\hline
\end{tabular}


The results of surface tension measurements compare favorably to reported values for similar solutions. The surface tension of pure water is reported as $72.75 \mathrm{mN} / \mathrm{m}$ at $20^{\circ} \mathrm{C}^{7}$. This is comparable to the measured values for the aqueous solutions, with surface tension values ranging from $62.3 \mathrm{mN} / \mathrm{m}$ to 72.7 $\mathrm{mN} / \mathrm{m}$. The surface tension for Isopar-L is reported as $25.9 \mathrm{mN} / \mathrm{m}^{8}$, similar to the measured TRUEX solutions which have surface tensions ranging from $25.2 \mathrm{mN} / \mathrm{m}$ to $35.0 \mathrm{mN} / \mathrm{m}$.

Unlike surface tension results, the interfacial tension measurements are considerably lower than the reported values for similar solvent pairs. Goebel and Lunkenhaimer reported interfacial tension for water $/ \mathrm{n}$-alkane systems with values ranging from $50.9 \mathrm{mN} / \mathrm{m}$ to $55.2 \mathrm{mN} / \mathrm{m}^{9}$. The TRUEX extraction and strip section solvent pairs have interfacial tension values of $10.2 \mathrm{mN} / \mathrm{m}$ and $13.2 \mathrm{mN} / \mathrm{m}$; respectively. This result indicates that the addition of nitric acid, TBP and/or CMPO causes a significant decrease in interfacial tension relative to similar solvent pairs with no additives.

\subsubsection{Distribution Coefficient}

A plot of the distribution coefficient data for yttrium partitioning between $3 \underline{\mathrm{M}}$ nitric acid and TRUEX pre-equilibrated with $3 \underline{M}$ nitric acid is shown in Figure 3. By design, drop contact experiments were conducted with dilute metal solutions that fell within the linear region of the equilibrium distribution curve. Yttrium was chosen for the drop contact experiment based on the equilibrium distribution coefficient predicted using the Argonne Model for Universal Solvent Extraction (AMUSE) code. The AMUSE code was developed by Argonne National Laboratory and is used to calculate concentration profiles and distribution coefficients for numerous metal and non-metal species for defined nuclear reprocessing solvent extraction flowsheets. The distribution coefficient predicted by AMUSE was 3.34. This is in good agreement to the measured value of 2.98 .

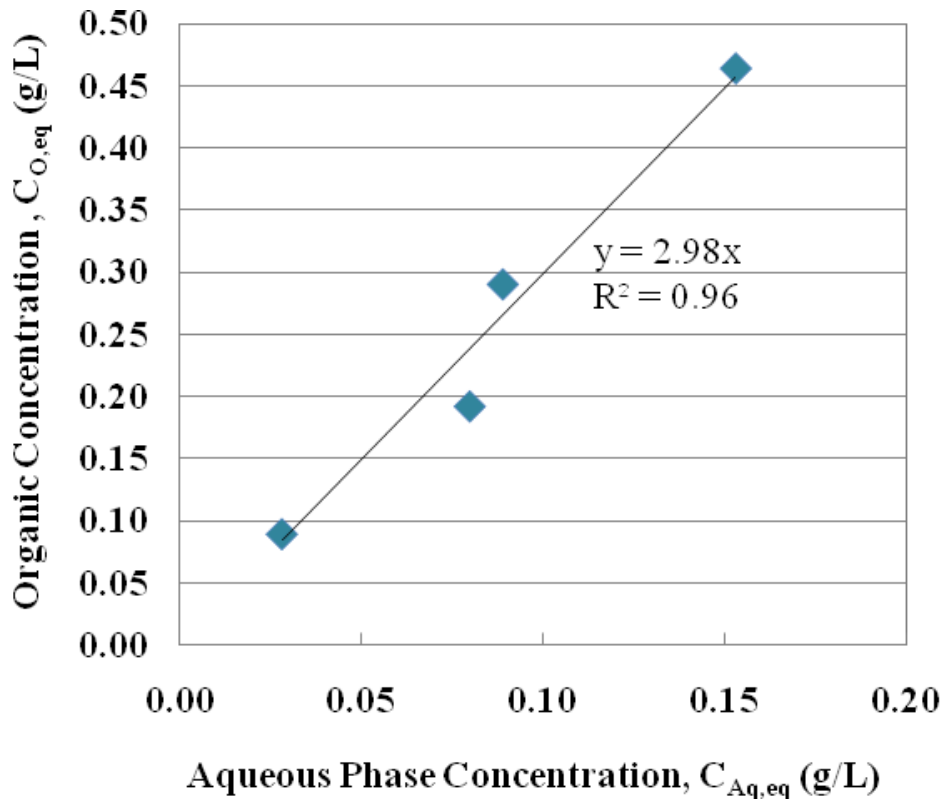

Figure 3. Yttrium distribution

\subsection{Drop Contact Experimental Results}

The mass transfer coefficient and velocity profile for yttrium under TRUEX extraction conditions were measured using the custom experimental apparatus. For this experiment, the aqueous solution was prepared with an initial yttrium concentration of $0.061 \mathrm{~g} / \mathrm{L}$, while the organic solution initially contained no metal. The organic solution was introduced into the apparatus at a flowrate of approximately 1.7 $\mathrm{mL} / \mathrm{min}$ through a needle orifice $0.82 \mathrm{~mm}$ in diameter. Samples of the organic drops were collected after each run and analyzed by ICP-MS to determine yttrium concentration. The yttrium concentration was then used to calculate the mass transfer coefficient as a function of time. 


\subsubsection{Drop Size and Deformation}

Drop diameter was determined using the high speed camera by comparing the number of pixels within an image of a drop to a reference distance. All needles were marked with $3 \mathrm{~mm}$ incremental markings for use as the reference distance. A single frame on the high speed camera was used to measure the pixel distance between the markings, giving a measure of distance per pixel. Then the pixels within a drop were measured, and the drop size was calculated. Three drops at each needle height were measured at various times.

Measurements were taken vertically and horizontally to provide measurements of each axis. There were no significant differences in drop size at the different needle heights, so an average drop size value as a function of time is reported.

The drop size measurements are presented in Table 5, and Figure 4 illustrates the deformation of the drops as a function of rise time. Figure 4 shows a period of slight oscillation until approximately 0.125 s. The data in Table 5 indicate that drops do not change shape considerably after $0.2 \mathrm{~s}$.

Table 5. Drop size

\begin{tabular}{ccc}
\hline Time $(\mathrm{s})$ & $\begin{array}{c}\text { Horizontal Diameter } \\
(\mathrm{mm})\end{array}$ & $\begin{array}{c}\text { Vertical Diameter } \\
(\mathrm{mm})\end{array}$ \\
\hline \hline 0.050 & $3.25 \pm 0.12$ & $3.16 \pm 0.14$ \\
0.100 & $3.42 \pm 0.18$ & $2.91 \pm 0.16$ \\
0.150 & $3.52 \pm 0.21$ & $2.77 \pm 0.09$ \\
0.200 & $3.61 \pm 0.24$ & $2.70 \pm 0.09$ \\
0.250 & $3.64 \pm 0.22$ & $2.69 \pm 0.09$ \\
0.300 & $3.67 \pm 0.22$ & $2.63 \pm 0.07$ \\
0.350 & $3.58 \pm 0.29$ & $2.63 \pm 0.08$ \\
\hline
\end{tabular}

For the purposes of calculating the mass transfer coefficient, the horizontal and vertical diameters were determined by averaging the measurements taken after $0.2 \mathrm{~s}$. The average values for the horizontal and vertical diameters are $3.62 \mathrm{~mm}$ and $2.66 \mathrm{~mm}$, respectively. The volume and surface area of the drops were calculated under the assumption that the drops take the shape of an oblate ellipsoid. The equatorial radii (along the $\mathrm{x}$ and $\mathrm{y}$ axes) are assumed to equal the average horizontal radius, while the polar radius (along the $\mathrm{z}$ axis) is equal to the average vertical radius.

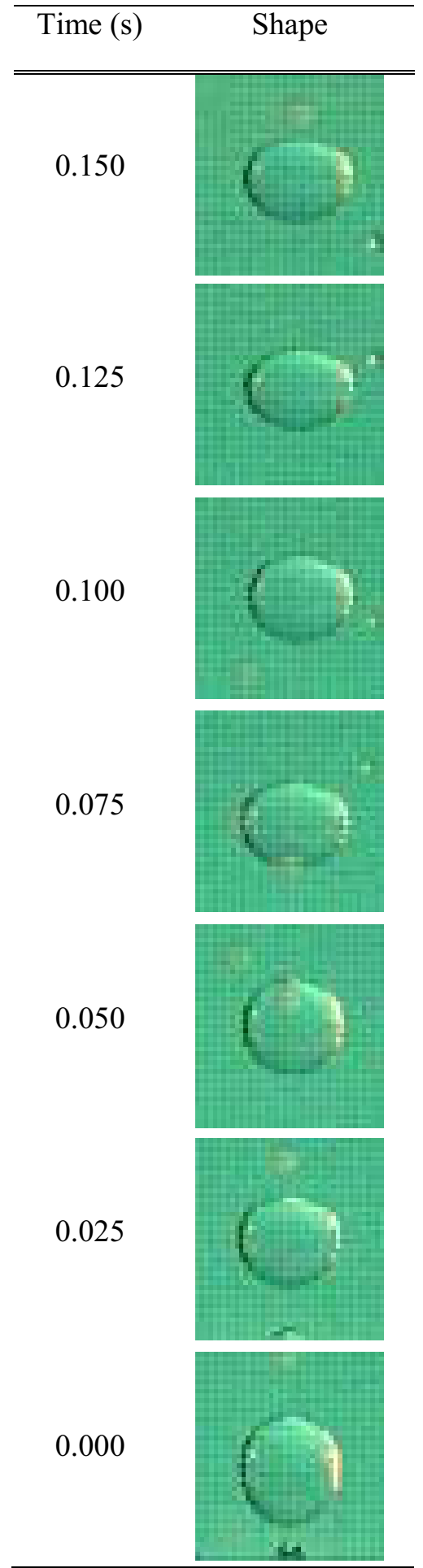

Figure 4. Drop deformation 
Based on the assumption of an oblate ellipsoid, the volume of a drop is calculated per Equation 3 and the surface area is calculated by Equations 4 and 5:

$$
\begin{gathered}
V_{O}=4 \pi a b c \\
A=2 \pi\left(a^{2}+c^{2} \frac{\operatorname{arctanh}(\sin (\alpha))}{\sin (\alpha)}\right) \\
\alpha=\arccos \left(\frac{c}{a}\right)
\end{gathered}
$$

Equation 3

Equation 4

Equation 5

where $\mathrm{a}$ and $\mathrm{b}$ are the equatorial radii, and $\mathrm{c}$ is the polar radius. Performing the calculations, results in a surface area of $34.2 \mathrm{~mm}^{2}$ and a volume of $18.3 \mathrm{~mm}^{3}$.

\subsubsection{Velocity}

The velocity profile of the drops was determined by measuring drop distance from the needle as a function of time. Three drops were measured at each needle height. The distance was measured every $0.01 \mathrm{~s}$ for the first $0.05 \mathrm{~s}$ and every $0.05 \mathrm{~s}$ thereafter. The drop distance vs. time data were input into the statistical software TableCurve ${ }^{\circledR}$, from Jandel Scientific, which used the data to calculate the velocity profile. Results are presented in Table 6 . Distance and velocity profile variations between needle heights were very small; therefore, the data are presented as an average value for all needle heights. The distance and velocity profiles are shown graphically in Figures 5 and 6; respectively. Figure 6 shows that the drops approach a maximum velocity of approximately $120 \mathrm{~mm} / \mathrm{s}$ around $0.2 \mathrm{~s}$, which is also the approximate time when the drop shape stabilizes.

Table 6. Distance and velocity

\begin{tabular}{ccc}
\hline Time $(\mathrm{s})$ & $\begin{array}{c}\text { Distance } \\
\text { Traveled }(\mathrm{mm})\end{array}$ & $\begin{array}{c}\text { Velocity } \\
(\mathrm{mm} / \mathrm{s})\end{array}$ \\
\hline \hline 0.000 & $1.3 \pm 0.1$ & 0.0 \\
0.010 & $1.9 \pm 0.1$ & 43.0 \\
0.020 & $2.3 \pm 0.2$ & 42.7 \\
0.030 & $2.8 \pm 0.1$ & 49.6 \\
0.040 & $3.3 \pm 0.2$ & 59.8 \\
0.050 & $4.0 \pm 0.2$ & 70.0 \\
0.100 & $8.3 \pm 0.2$ & 97.3 \\
0.150 & $13.5 \pm 0.3$ & 109.4 \\
0.200 & $19.2 \pm 0.5$ & 118.1 \\
0.250 & $25.3 \pm 0.6$ & 123.6 \\
0.300 & $31.5 \pm 0.6$ & 125.1 \\
0.350 & $37.7 \pm 0.5$ & 122.0 \\
\hline
\end{tabular}


Fundamental Drop Dynamics and Mass Transfer Experiments to Support Solvent Extraction Modeling Efforts

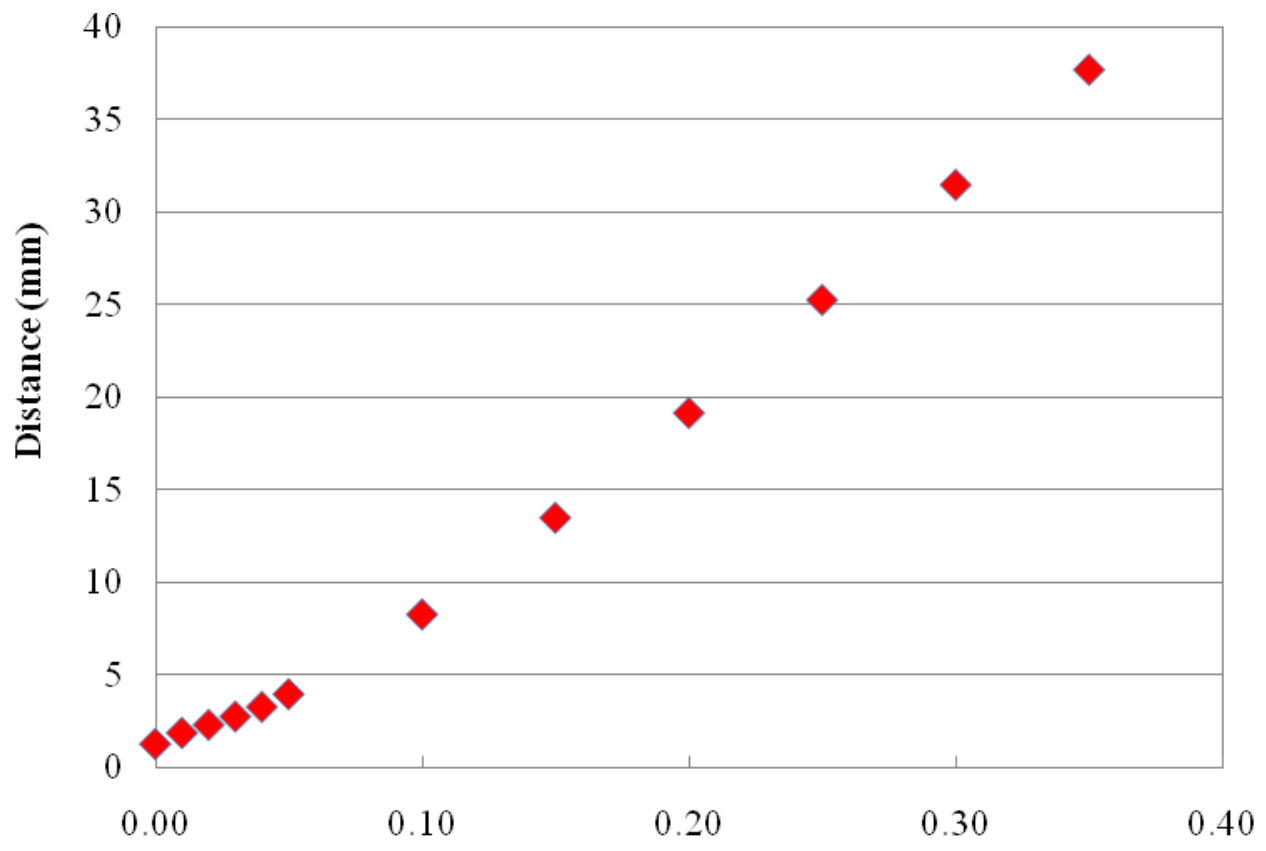

Time (s)

Figure 5. Distance profile

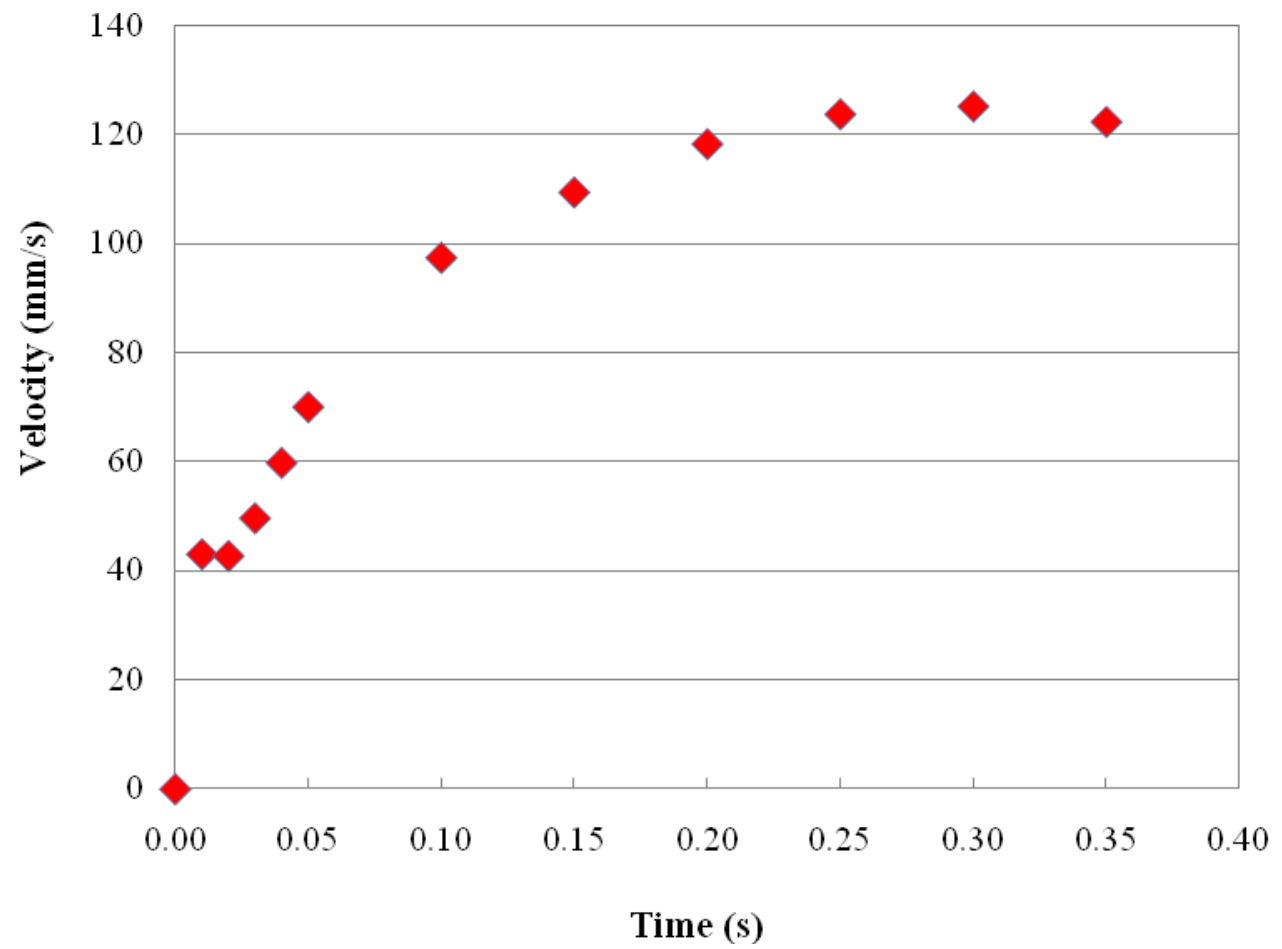

Figure 6. Velocity profile 
The experimentally determined velocity profile does not compare well to preliminary output of the LANL model. The experiment was designed to introduce drops into the apparatus with as little velocity as possible, allowing drops to rise entirely by buoyancy. Drops rising by buoyancy will start at a velocity of zero and accelerate to approach a terminal velocity where the force of buoyancy is balanced by drag forces. This type of profile was predicted by the LANL model and was observed experimentally. However, the terminal velocity measured in the experiment was approximately $120 \mathrm{~mm} / \mathrm{s}$, while the model predicts a value of only $90 \mathrm{~mm} / \mathrm{s}$. One area where the model and experimental data agree is that both approach terminal velocity at approximately $0.2 \mathrm{~s}$.

One possible explanation for the disagreement between model predictions and experimental data can be found in results reported by Wegener et al. in a study that evaluated mass transfer and velocity profiles of single drops in a toluene/acetone/water system. Wegener et al. found that drops larger than $2 \mathrm{~mm}$ in diameter accelerated to pseudo-terminal velocities within approximately $0.5 \mathrm{~s}$, and then slowed to lower final velocities due to increasing drag forces caused by drop deformation. The reduction in velocity did not occur until after $1 \mathrm{~s}$ of rise time. Since the current study only evaluated velocity up to $0.4 \mathrm{~s}$, it is possible that only a pseudo terminal velocity was observed experimentally.

\subsubsection{Mass Transfer Coefficient}

Table 7 shows concentration results and rise times obtained during the drop contact experiment. The concentration of the aqueous phase was measured before and after each run to validate the assumption of constant aqueous phase concentration. Rise time was measured by multiplying the frame rate of the high speed camera by the number of frames that elapsed between the drop disengaging from the needle and reaching the neck of the organic collection funnel. This was measured for 4 drops per needle height. The average rise time is reported.

Table 7. Drop contact experimental data

\begin{tabular}{ccccc}
\hline $\begin{array}{c}\text { Needle } \\
\text { Height }\end{array}$ & Rise Time $(\mathrm{s})$ & $\begin{array}{c}\text { Initial Aqueous } \\
\text { Concentration } \\
(\mathrm{g} / \mathrm{L})\end{array}$ & $\begin{array}{c}\text { Final Aqueous } \\
\text { Concentration } \\
(\mathrm{g} / \mathrm{L})\end{array}$ & $\begin{array}{c}\text { Organic } \\
\text { Concentration } \\
(\mathrm{g} / \mathrm{L})\end{array}$ \\
\hline \hline 1 & $0.213 \pm 0.001$ & 0.0606 & 0.0638 & 0.0037 \\
2 & $0.562 \pm 0.003$ & 0.0588 & 0.0581 & 0.0066 \\
3 & $1.148 \pm 0.090$ & 0.0635 & 0.0625 & 0.0094 \\
4 & $1.515 \pm 0.021$ & 0.0641 & 0.0561 & 0.0130 \\
5 & $1.942 \pm 0.018$ & 0.0573 & 0.0609 & 0.0168 \\
6 & $2.490 \pm 0.021$ & 0.0618 & 0.0597 & 0.0195 \\
\hline
\end{tabular}

Assumptions made for calculating the mass transfer coefficient are constant aqueous phase volume, negligible species concentration gradient in the aqueous phase, and constant drop size between needle heights. The aqueous phase volume was held constant by design throughout the experiment. The ICPMS aqueous phase concentration data, shown in Table 7, validate the assumption of negligible species concentration gradient in the aqueous phase. The assumption of constant drop size was confirmed by performing measurements of drops at different needle heights using the high speed digital camera. The governing equations for calculating the mass transfer coefficient are those for the equilibrium of the species between phases (Equation 6) and accumulation of the species in the organic phase (Equation 7).

$$
C_{o, e q}=m C_{a q}
$$




$$
\frac{\partial C_{0}}{\partial t}=\frac{k A}{V_{0}}\left(C_{o, \theta q}-C_{o}\right)
$$

Equation 7

where $\mathrm{C}$ is concentration, $\mathrm{m}$ is distribution coefficient, $\mathrm{k}$ is mass transfer coefficient, $\mathrm{V}$ is volume, $\mathrm{A}$ is interfacial surface area, and $t$ is time. The subscripts o, aq, and eq represent organic, aqueous, and equilibrium conditions, respectively. Substitution of Equation 6 into Equation 7, and solving for k results in Equation 8:

$$
k=\frac{\left(\frac{\partial C_{o}}{\partial t}\right) \times V_{o}}{A\left(m C_{a q}-C_{0}\right)}
$$

Equation 8

To determine the accumulation of metal in the organic phase as a function of time $\left(\frac{\partial C_{0}}{\partial t}\right)$ and to express $\mathrm{C}_{\mathrm{O}}$ as a function of time, a plot of organic concentration vs. time was prepared. This plot is shown in Figure 7.

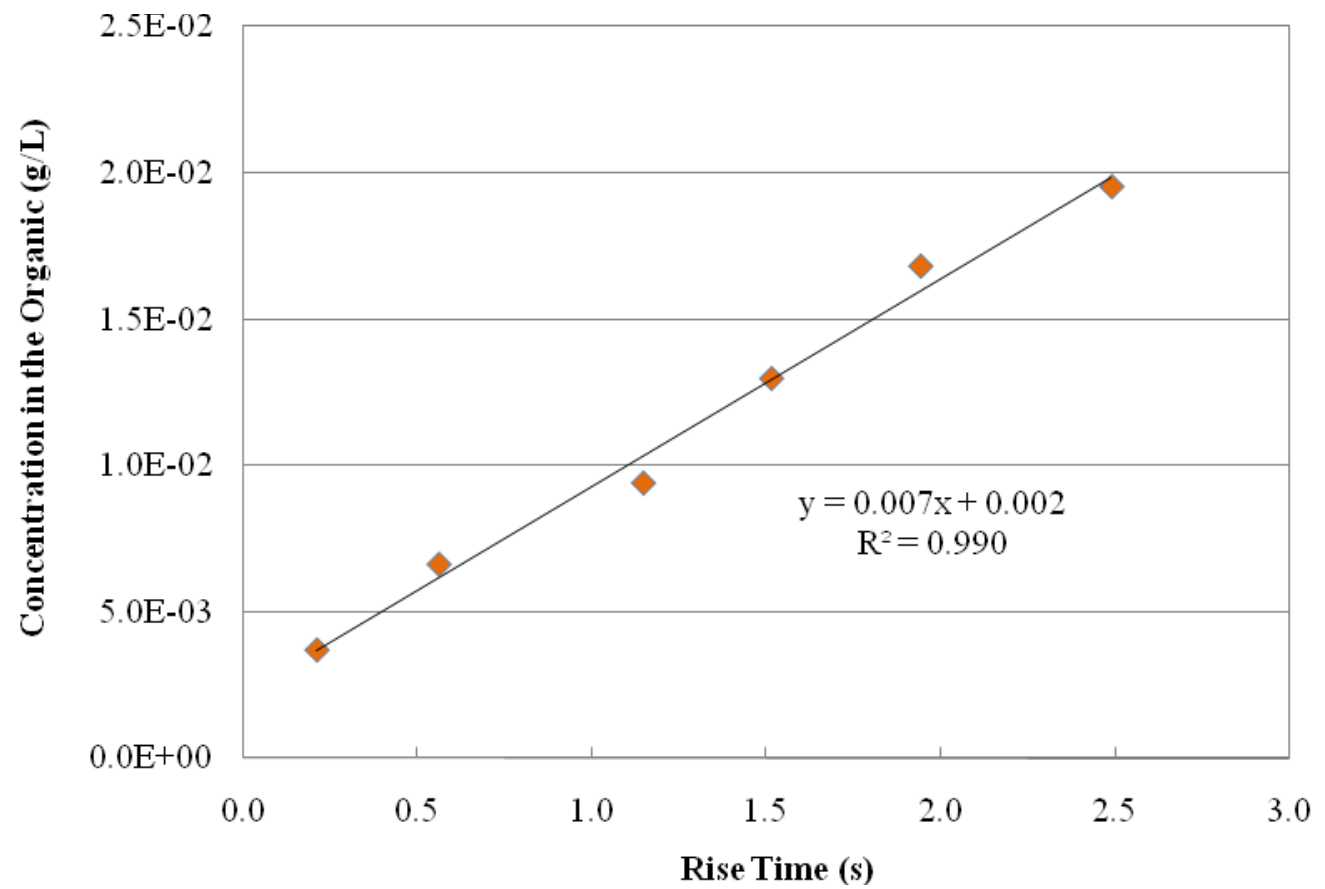

Figure 7. Concentration in the organic drop as a function of time

The linearity of the plot indicates that the accumulation rate $\left(\frac{\partial C_{0}}{\partial t}\right)$ of metal in the organic drop was constant with time, with a value of $0.007 \mathrm{~g} / \mathrm{L}-\mathrm{s}$.

The organic concentration as a function of time is expressed by Equation 9. The y-intercept is excluded from the function to correct for mass transfer that occurred during drop formation and coalescence. This correction results in a boundary condition of $\mathrm{C}_{\mathrm{O}}=0$ at $\mathrm{t}=0$, where $\mathrm{t}=0$ is defined as the time when the drop disengages from the needle.

$$
C_{O}=0.007 \frac{g}{L \cdot s} * t
$$

Equation 9

Equation 8 can now be simplified to express the mass transfer rate as a function of time by inputting the experimentally determined values for all parameters and substituting Equation 9 for $\mathrm{C}_{\mathrm{O}}$. The constants 
used in the equation are summarized in Table 8. The value for $\mathrm{C}_{\mathrm{Aq}}$ is the average value for all initial and final aqueous phase samples measured by ICP-MS found in Table 7.

Table 8. Mass transfer coefficient calculation parameters

\begin{tabular}{cc} 
Parameter & Value \\
\hline \hline$\frac{\partial C_{s}}{\partial t}$ & $0.007 \mathrm{~g} / \mathrm{L}-\mathrm{s}$ \\
$\mathrm{V}_{\mathrm{O}}$ & $18.3 \mathrm{~mm}^{3}$ \\
$\mathrm{~A}$ & $34.2 \mathrm{~mm}^{2}$ \\
$\mathrm{~m}$ & 2.98 \\
$\mathrm{C}_{\mathrm{Aq}}$ & $0.0606 \mathrm{~g} / \mathrm{L}$ \\
\hline
\end{tabular}

Inputting the values and rearranging, the equation becomes:

$$
k=\frac{0.021}{(1-0.039 t)}
$$

where time ( $\mathrm{t}$ ) is in seconds, and $k$ has units of $\mathrm{mm} / \mathrm{s}$.

A plot of k vs. time is presented in Figure 8.

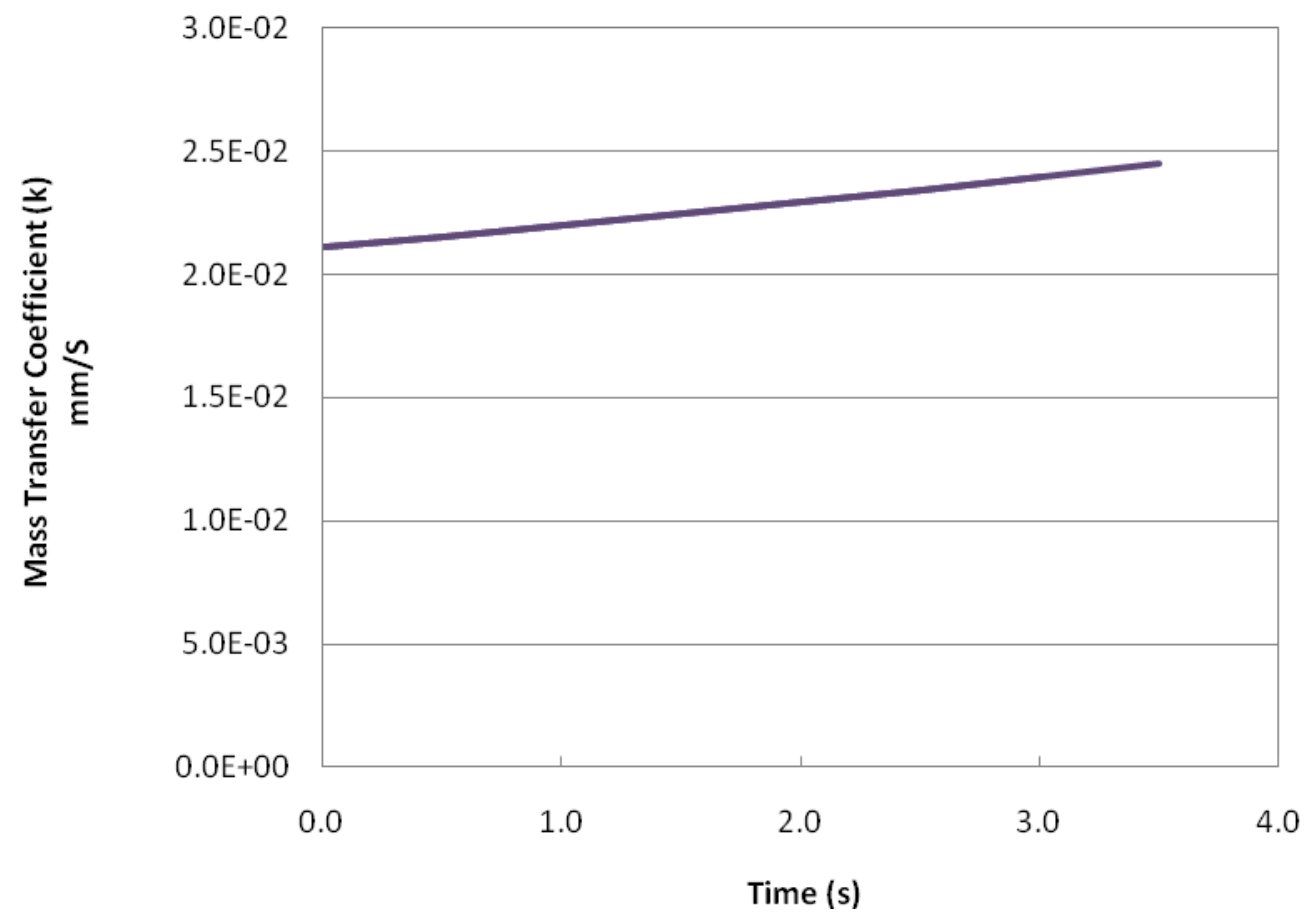

Figure 8. Mass transfer coefficient as a function of time 
The inverse of the mass transfer coefficient $(1 / \mathrm{k})$ is used to account for the resistance to mass transfer. The driving force for mass transfer is the concentration difference between the concentration in the drop and the concentration in the drop that would be in equilibrium with the concentration in the aqueous phase $\left(\mathrm{mC}_{\mathrm{Aq}}-\mathrm{C}_{\mathrm{O}}\right)$. An increase in the resistance to mass transfer is expected as the concentration in the drop approaches equilibrium, corresponding to a decrease of the mass transfer coefficient. Therefore, the expected trend is a mass transfer coefficient that decreases with time as metal is transferred to the drop. However, this trend was not observed. The mass transfer coefficient appears to increase linearly with time.

The most likely reason that the mass transfer coefficient did not follow the expected trend is that the actual concentration in the organic drop was significantly below the concentration that would be in equilibrium with the aqueous phase $\left(\mathrm{mC}_{\mathrm{A}}>>\mathrm{C}_{\mathrm{O}}\right)$, meaning that the system was far from achieving equilibrium. A system that is far from equilibrium could behave as if the concentration in the organic phase is negligible. If the assumption is made that $C_{O}$ is approximately zero, then the mass transfer rate becomes constant with a calculated value of $\mathrm{k}=0.021 \mathrm{~mm} / \mathrm{s}$.

\section{CONCLUSION}

At the completion of this project, the INL has gathered a complete set of experimentally determined fluid parameters that can be used as input data into the model being developed at LANL. The fluid properties of density, viscosity, surface tension, and interfacial tension were measured. With the exception of interfacial tension, measured values compare favorably to reported values of similar solutions. The interfacial tension is believed to be relatively low due to additives, such as CMPO and nitric acid, in the TRUEX solvent pairs. Diffusion coefficients for yttrium in TRUEX extraction section solvents were measured. While there was no data available for comparison to the organic phase diffusion coefficient, the aqueous phase diffusion coefficients matched well with reported values for similar solutes in acidic aqueous solutions. The distribution coefficient for yttrium partitioning between $3 \underline{\mathrm{M}}$ nitric acid and TRUEX solvent pre-equilibrated with $3 \underline{\mathrm{M}}$ nitric acid was measured and found to be in good agreement with the estimated value predicted using the AMUSE modeling code.

A drop contact experiment using a custom designed experimental apparatus was also completed. The experiment examined the yttrium transferring between TRUEX extraction solutions. Results indicate that at the conditions tested, the accumulation of metal in the organic drop was constant at a rate of $0.007 \mathrm{~g} / \mathrm{L}$ $\mathrm{s}$. The system was far from achieving equilibrium, resulting in a constant mass transfer coefficient of $\mathrm{k}=$ $0.021 \mathrm{~mm} / \mathrm{s}$.

There are several opportunities for future work associated with this project. Experiments evaluating the velocity profile of a rising drop for an extended time period would be useful to compare experimental results to model predictions. Multiple drop sizes could be tested to determine the impacts of drop size on drop deformation, drop velocity, and mass transfer rate. Altering experiments to test a system closer to equilibrium would be of interest to better define the relationship between contact time and mass transfer coefficient. And finally, experiments performed with cerium would provide values for mass transfer coefficients that are representative of mass transfer observed in actual TRUEX processing, and would be useful is assessing how varying distribution coefficients affect mass transfer rates. 


\section{ACKNOWLEDGMENTS}

- The authors would like to acknowledge Russel Lewis of the INL for his glassblowing expertise and his assistance with construction of the drop contact experiment apparatus.

- The authors would like to acknowledge the INL Biofuels and Renewable Energy Technology Department for use of their high speed digital camera, with special thanks to Randy Bewley for time spent training us on the use of the camera.

- The authors would like to acknowledge Dr. Harry Rollins and Dr. Mason Harrup of the INL for their assistance with viscosity measurement.

- The authors would like to acknowledge Brandi Grover, a summer intern at the INL, for her hard work in the laboratory preparing solutions and assisting with experiments.

- The authors would like to acknowledge University of Idaho Department of Chemical Engineering professor Eric Aston and University of Idaho graduate student Jamie Jabal for their work measuring interfacial and surface tension.

- The authors would like to acknowledge Byron White of the INL for his expertise and assistance in conducting ICP-MS analyses.

- The authors would like to acknowledge Rich Tillotson and Lonnie Olson of the INL for their assistance with the radiotracer work associated with measuring diffusion coefficients.

- And finally, the authors would like to acknowledge Marianne Francois of LANL for her hard work on the modeling effort connected to this project, as well as for her input on the direction of the experimental work being performed at INL. 


\section{REFERENCES}

${ }^{1}$ Latrous, H.: Oliver, J., "Self-Diffusion Coefficients and Structure of the Trivalent Transplutonium Ion Berkelium in Aqueous Solution," Journal of Molecular Liquids 81, 115-121 (1999)

${ }^{2}$ Ouerfelli, N.; Ammar, M.; Latrous, H.; "Ionic Self-Diffusion Coefficients of ${ }^{153} \mathrm{Gd}$ (III) in $\mathrm{Gd}\left(\mathrm{NO}_{3}\right)_{3}$ Solutions in Water-Dioxan Mixtures at $25^{\circ} \mathrm{C}$," J. Phys.: Condesn. Matter 8, 8173-8181 (1996)

${ }^{3}$ Matsuda, T.; Gonda, K.; "Mass Transfer Coefficients of Uranium and Plutonium across Aqueous/Organic Interfaces of Solvent Extraction," Journal of Nuclear Science and Technology 23, 529539 (1986)

${ }^{4}$ Steiner, L.; Oezdemir, G.; Hartland, S.; "Single-Drop Mass Transfer in the Water-Toluene Acetone System,” Ind. Eng. Chem. Res. 29, 1313-1318 (1990)

${ }^{5}$ Wegener, M.; Grünig, J.; Stüber, J.; Paschedag, A. R.; Kraume M.; “Transient Rise Velocity and Mass Transfer of a Single Drop with Interfacial Instabilities-Experimental Investigations," Chemical Engineering Science 62, 2967-2978, (2007)

${ }^{6}$ Hashem, M. A.; El-Bassuoni, A. A.; "Drop Formation Mass Transfer Coefficients in Extraction Columns," Thoeretical Foundations of Chemical Engineering 41, 506-511 (2007)

${ }^{7}$ Lide, D. R. Ed.; CRC Handbook of Chemistry and Physics, $86^{\text {th }}$ Edition (2005-2006)

${ }^{8}$ Isopar-L Material Safety Data Sheet provided by Exxon (2010)

${ }^{9}$ Goebel A.; Lunkenhaimer K.; "Interfacial Tension of the Water/n-Alkane Interface," Langmuir 13, 369372 (1997) 